\title{
Desempenho de híbridos de milho em diferentes arranjos espaciais de plantas
}

\author{
Claudinei Kappes $\left({ }^{(*}\right)$; João Antonio da Costa Andrade ( $\left.{ }^{2}\right)$; Orivaldo Arf ( $\left.{ }^{3}\right)$; Angela Cristina de \\ Oliveira ('); Marcelo Valentini Arf ('); João Paulo Ferreira (')
}

(') Universidade Estadual Paulista "Julio de Mesquita Filho" (UNESP/FEIS), Programa de Pós-Graduação em Agronomia/Sistemas de Produção, Avenida Brasil, 56, Centro, 15385-000, Itha Solteira (SP)

(2) UNESP/FEIS, Departamento de Biologia e Zootecnia,15385-000 Itha Solteira (SP).

(3) UNESP/FEIS, Departamento de Fitotecnia, Tecnologia de Alimentos e Sócio-Economia, 15385-000 Ilha Solteira (SP).

(*) Autor correspondente: kappes.agro@gmail.com

Recebido: 23/fev./2010; Aceito: 21/set./2010.

\section{Resumo}

As modificações introduzidas recentemente nos genótipos de milho tem tornado necessário reavaliar as recomendações de práticas de manejo para esta cultura, dentre elas, o arranjo espacial de plantas. Este trabalho foi realizado com o objetivo de verificar o melhor arranjo de plantas para os híbridos de milho XB 6010, XB 6012, XB 7253, XB 9003 e AG 9010 nos espaçamentos entre linhas de 0,45 e 0,90 m e nas populações de 50.000, 60.000, 70.000, 80.000 e 90.000 plantas ha-1. 0 experimento foi realizado em 2009, em Selvíria (MS), em blocos ao acaso com os dois espaçamentos dispostos em faixas dentro de cada bloco e as 25 combinações híbridos x populações casualisadas dentro de cada espaçamento. Os resultados foram submetidos ao teste $F$, sendo os efeitos de híbridos e de espaçamentos comparados pelo teste de Tukey $(p<0,05)$ e de populações pela análise de regressão. Independentemente de híbrido e de população, o espaçamento influenciou apenas o diâmetro de colmo, e a utilização de 0,45 m entre linhas proporcionou a obtenção de plantas com maior diâmetro. Diâmetro de colmo, comprimento e diâmetro de espiga, prolificidade e massa de cem grãos diminuíram de forma linear à medida que se aumentou a população de plantas, ao passo que a altura de planta não foi afetada. Os melhores arranjos foram: AG 9010 - 90.000 plantas ha-1 no espaçamento de 0,45 m; XB 7253 - 72.000 plantas ha-1 em ambos os espaçamentos; e XB 6010, XB 6012 e XB 9003 - sem resposta significativa aos arranjos, podendo ser recomendado 50.000 plantas ha-1 nos dois espaçamentos.

Palavras-chave: Zea mays, espaçamento entre linhas, população de plantas.

\section{Performance of corn hybrids in different space arrangements of plants}

\section{Abstract}

Due to recenthy introduced maize genotypes, the reassessement of recommendations of management practices is necessary, among them, the spatial arrangement of plants. In this way, this study has as aim to evaluate the best plant arrangement for the corn hybrids XB 6010, XB 6012, XB 7253, XB 9003 and AG 9010 in spacings between rows of 0.45 and 0.90 $\mathrm{m}$ and at populations of 50,000,60,000, 70,000, 80,000 and 90000 plants ha ${ }^{-1}$. The experiment was carried out on the crop year of 2009 in Selvíria (MS), following a randomized block design with two spaces arranged in bands within each block and the 25 combinations hybrid $x$ populations randomized within spacing. The results were submitted to $F$ test, with the effects of hybrids and spacing compared by Tukey test $(p<0.05)$ and populations by regression analysis. Independent of hybrid and population, the spacing influenced only the stalk diameter, and the use of $0.45 \mathrm{~m}$ between rows proportioned the production of plants with larger stalk diameter. Stalk diameter, ear length, ear diameter, prolificacy and weight of one hundred grains decreased linearly with increasing plant population, while plant height was not affected. The best arrangements were: AG 9010 with 90,000 plants ha ${ }^{-1}$ and spacing of $0.45 \mathrm{~m}$; XB 7253 with 72,000 plants ha ${ }^{-1}$ in both row spacings; and as XB 6010 , XB 6012 and XB 9003 did not respond to such arrangements, being recommended 50,000 plants ha ${ }^{-1}$ in the two spacings.

Key words: Zea mays, row spacing, plant population 


\section{INTRODUÇÃO}

O crescente aumento do consumo mundial de milho tem levado a uma pressáo cada vez maior para aumento da produção deste cereal. Contudo, o rendimento de grãos do milho é uma variável complexa e depende da interação entre fatores genéticos, ambientais e de manejo. No Brasil, o rendimento do milho é muito baixo, em decorrência de fatores ligados à fertilidade do solo, arranjo espacial de plantas (Fancelli e Dourado Neto, 2004), uso de genótipos e práticas de manejo inadequadas (SANGOI et al., 2006). Na safra 2009/2010, o rendimento médio do milho total, que compreende a primeira e segunda safra, foi de $4.130 \mathrm{~kg} \mathrm{ha}^{-1}$ (CONAB, 2010).

A manipulação do arranjo espacial de plantas pela alteração no espaçamento e na densidade de plantas na linha tem sido apontada como uma das práticas de manejo mais importantes para maximizar o rendimento de grãos do milho, pela otimizaçáo do uso de fatores de produção como água, luz e nutrientes (Argenta et al., 2001; Dourado Neto et al., 2003; Demétrio et al., 2008). Recentemente, estudos objetivando a determinação do melhor arranjo espacial de plantas, nessa cultura, têm sido discutidos com maior frequência, decorrente das variaçôes morfológicas e genéticas apresentadas pelos híbridos atuais e do surgimento de novos genótipos e técnicas de manejo para a cultura, utilizando-se híbridos com elevado potencial produtivo (Argenta et al., 2001; SANGOI et al., 2006). Especificamente para o milho, sob densidade excessiva de plantas, condição em que a perda de produção individual é superior ao ganho com aumento de plantas por área, pode ocorrer defasagem entre os florescimentos masculino (pendoamento) e feminino (espigamento), resultando em menor polinização (RodRIGUES et al., 2009), consequentemente reduzindo o número de grãos por espiga.

A obtenção de novos híbridos, cada vez mais produtivos, gera a necessidade de avaliá-los em grande amplitude de condições edafoclimáticas (CARDoso et al., 2003), demandando por práticas de manejo mais adequadas para maximizar o potencial produtivo da cultura. Normalmente, a determinação do melhor arranjo de plantas é feita após a obtenção dos híbridos que, por motivos de praticidade, ainda não foram submetidos a avaliaçốes mais detalhadas nesse aspecto. Em contrapartida, informaçôes para quantificar o efeito do aumento da população de plantas na cultura do milho são essenciais e ao mesmo tempo escassas no Brasil. A despeito da carência de informaçôes, alguns agricultores têm adotado, com sucesso, populações de plantas de até 72.000 plantas ha $^{-1}$ e espaçamento entre linhas de 0,40 m (Fancelli e Dourado Neto, 2004).

Em virtude das modificações introduzidas nos genótipos de milho mais recentes, tais como menor estatura de planta e altura de inserção de espiga, menor esterilidade de plantas, menor duração do subperíodo pendoamento- espigamento, plantas com folhas de angulação mais ereta e elevado potencial produtivo, torna-se necessário reavaliar as recomendaçôes de práticas de manejo para novos genótipos (ARGENTA et al., 2001), dentre elas, o melhor arranjo espacial de plantas.

Diante do exposto, o presente estudo teve como objetivo verificar o melhor arranjo de plantas, em dois espaçamentos entre linhas, para cinco híbridos de milho.

\section{MATERIAL E MÉTODOS}

O experimento foi instalado no município de Selvíria, Estado de Mato Grosso do Sul, em área experimental situada a aproximadamente $20^{\circ} 20^{\prime}$ Sul e $51^{\circ} 24^{\prime}$ Oeste, com $350 \mathrm{~m}$ de altitude. O clima da região, segundo classificação de Köppen, é do tipo Aw, com precipitação pluvial média anual de $1.330 \mathrm{~mm}$, temperatura média anual de $25^{\circ} \mathrm{C}$ e umidade relativa do ar média anual de $66 \%$. O solo da área experimental é classificado como Latossolo Vermelho distrófico álico e de textura argilosa (EMBrapa, 2006), cuja análise química (camada de 0 a 0,2 m) revelou os valores: $\mathrm{MO}: 28 \mathrm{~g} \mathrm{dm}^{-3} ; \mathrm{pH}\left(\mathrm{CaCl}_{2}\right)$ : 5,4; P (resina); S, B, Cu, Fe, Mn e Zn: 15, 1, 0,25, 2,9, 22, 26,6 e 0,6 $\mathrm{mg} \mathrm{dm}^{-3}$ respectivamente; $\mathrm{K}, \mathrm{Ca}, \mathrm{Mg}$, $\mathrm{H}+\mathrm{Al}$ e CTC: $3,4,24,15,25$ e $67,4 \mathrm{mmol}_{\mathrm{c}} \mathrm{dm}^{-3}$ respectivamente; e V: 63\%.

Foram estabelecidos cinquenta tratamentos com quatro repetiçôes, resultantes da combinação dos fatores híbridos de milho, espaçamentos e populaçóes de plantas. O delineamento experimental foi o de blocos ao acaso, em esquema misto de faixas e fatorial. Os espaçamentos foram dispostos em faixas dentro de cada bloco e as 25 combinaçôes híbridos x populaçóes locadas em esquema fatorial $5 \times 5$ dentro de cada e espaçamento. Portanto, as 50 combinaçốes (2 espaçamentos x 5 híbridos x 5 populaçôes) participaram de cada bloco, mas os espaçamentos não foram totalmente casualizados como os híbridos e as populaçóes. Foram utilizados os seguintes híbridos recomendados para o cultivo na região visando à produção de grãos: XB 6010 (simples e superprecoce), XB 6012 (simples e precoce), XB 7253 (triplo e precoce), XB 9003 (simples e superprecoce) e AG 9010 (simples e superprecoce). O AG 9010 é considerado de arquitetura moderna, com menor altura de plantas, folhas mais estreitas e eretas. Os demais são de maior estatura, com folhas largas e horizontais. Os espaçamentos foram de 0,45 e $0,90 \mathrm{~m}$ entre linhas e as populaçôes de 50.000, 60.000, 70.000, 80.000 e 90.000 plantas ha $^{-1}$.

As parcelas foram constituídas por sete e quatro linhas de 4,5 m de comprimento para os espaçamentos entre linhas de 0,45 e $0,90 \mathrm{~m}$ respectivamente, perfazendo área total de $14,2 \mathrm{~m}^{2}$ e $16,2 \mathrm{~m}^{2}$, respectivamente. Para coleta dos dados foram utilizadas somente as quatro e as duas linhas centrais nos espaçamentos de 0,45 e $0,90 \mathrm{~m}$ 
respectivamente. A área útil foi de $8,1 \mathrm{~m}^{2} \mathrm{em}$ ambos os espaçamentos.

O experimento foi instalado há 12 anos, em área cultivada em sistema plantio direto a qual foi ocupada com feijão no período de inverno do ano agrícola de 2008 , permanecendo em pousio no verão seguinte. $\mathrm{Na}$ semana que antecedeu a semeadura, as plantas daninhas presentes na área, na qual predominavam a trapoeraba (Commelina benghalensis L.) e a nabiça (Raphanus raphanistrum L.), foram dessecadas com glyphosate (1920 g ha $^{-1}$ do i.a.). A adubaçáo mineral foi realizada de acordo com as características químicas do solo e nas recomendaçôes propostas por RAIJ et al. (1996), com rendimento esperado de $8 \mathrm{t} \mathrm{ha}^{-1}$. Foram aplicados $260 \mathrm{~kg} \mathrm{ha}^{-1} \mathrm{da}$ fórmula 08-28-16 (mais $1 \%$ de $\mathrm{Ca}, 2 \%$ de $\mathrm{S}$ e $0,3 \%$ de $\mathrm{Zn}$ ), ajustando-se a distribuição do fertilizante para cada espaçamento utilizado. A abertura dos sulcos e a distribuição do fertilizante foram realizadas com semeadora específica para o sistema plantio direto, com mecanismo sulcador de hastes (tipo "botinha").

As sementes de milho foram tratadas com inseticida tiodicarbe $\left(1050 \mathrm{~g} 100 \mathrm{~kg}\right.$ de sementes ${ }^{-1}$ do i.a. $)$ e a semeadura foi realizada em 20 de março de 2009, com matracas, sendo as covas espaçadas de forma eqüidistante, de acordo com a populaçáo desejada e o espaçamento utilizado. Após a semeadura, a área foi irrigada por aspersão por sistema de irrigaçáo do tipo pivô central, com uma lâmina de água de aproximadamente $13 \mathrm{~mm}$ para promover a germinação e emergência uniforme das plântulas, que ocorreu cinco dias após a semeadura. Foi semeado o dobro da quantidade de sementes, e realizado o desbaste quando as plantas estavam com sete folhas expandidas, deixando-se uma planta por cova, objetivando ajustar as populaçóes desejadas.

A adubaçáo de cobertura foi realizada quando em $50 \%$ das plantas havia seis folhas expandidas, aplicandose $110 \mathrm{~kg} \mathrm{ha}^{-1}$ de $\mathrm{N}$ na forma de uréia $(45 \%$ de N). A aplicação do fertilizante foi de forma mecanizada em cobertura a lanço (sem incorporação), seguida de irrigação por aspersão (lâmina de aproximadamente $13 \mathrm{~mm}$ ) para minimizar as perdas de $\mathrm{N}$ por volatilização da amônia, conforme ressaltado por Costa et al. (2004). O fornecimento de água à cultura, nos períodos de estiagem, foi realizado por aspersão com lâmina de água de aproximadamente $13 \mathrm{~mm}$ e turno de rega de três dias especialmente nas fases de enchimento de grãos.

As plantas daninhas foram controladas em pós-emergência utilizando-se os herbicidas atrazina e tembotriona $\left(1000+84 \mathrm{~g} \mathrm{ha}^{-1}\right.$ do i.a. respectivamente), na forma de mistura. Adicionou-se na calda de aplicação o adjuvante éster metilado de óleo de soja ( $720 \mathrm{~g} \mathrm{ha}^{-1}$ do i.a.). No momento da aplicaçáo, as plantas daninhas estavam nos estádios iniciais de desenvolvimento e na cultura havia 50\% das plantas com cinco folhas expandidas. Para o controle da lagarta do cartucho [Spodoptera frugiperda (J.E. Smith)], foi reali- zada uma aplicação de zetacypermethrin (20 $\mathrm{g} \mathrm{ha}^{-1}$ do i.a.). As aplicaçôes dos produtos fitossanitários foram realizadas mediante o uso de pulverizador de barras tratorizado, com volume de calda equivalente a $220 \mathrm{~L} \mathrm{ha}^{-1}$.

Por ocasiáo do florescimento pleno das plantas de milho, foram mensurados, em cinco plantas por parcela, as seguintes características: altura de planta (medição do colo até a inserção da folha "bandeira") e da espiga (medição do colo até a inserção da primeira espiga viável) e diâmetro de colmo (diâmetro do segundo internódio, a partir da base da planta).

A colheita foi realizada em 28 de julho de 2009 (130 dias após a semeadura), sendo avaliado: comprimento e diâmetro de espiga (porção mediana da espiga), prolificidade (relação entre o número de espigas colhidas e o número de plantas na área útil da parcela) e massa de cem gráos (pesagem de uma subamostra de cem grãos por parcela, com a massa corrigida para $130 \mathrm{~g} \mathrm{~kg}^{-1}$ de teor de água - base úmida - "b.u."). Foram utilizadas 10 espigas ao acaso em cada parcela.

O rendimento de grãos foi obtido a partir da debulha e pesagem dos grãos oriundos de todas as espigas colhidas na área útil das parcelas, o qual foi convertido para $\mathrm{kg} \mathrm{ha}^{-1}$ e corrigido para $130 \mathrm{~g} \mathrm{~kg}^{-1}$ de teor de água (b.u.). O teor de água dos grãos foi obtido pelo método elétrico não destrutivo indireto, mediante o uso do aparelho portátil Multigrain (Dickey-John"), o qual propicia leitura direta.

Os resultados foram submetidos ao teste $\mathrm{F}$ da análise de variância (ANOVA). Os efeitos de híbridos e espaçamentos foram comparados pelo teste de Tukey a 5\% de probabilidade, de acordo com Pimentel Gomes e GarCIA (2002). O efeito de populações de plantas foi analisado por meio da análise de regressão polinomial, considerando-se apenas as equaçóes significativas pelo teste $\mathrm{F}$ $(\mathrm{p}<0,05)$. Utilizou-se o software SAS para as análises.

\section{RESULTADOS E DISCUSSÃO}

Os dados climáticos (Figura 1) indicam que durante a realização do experimento, a temperatura do ar, fator que intervém nas funçóes fisiológicas da planta, foi adequada para o desenvolvimento da cultura, haja vista que o milho produz melhor em temperaturas moderadas (DiDONET et al., 2002), entre 18 e $25^{\circ} \mathrm{C}$. Durante o ensaio, constatouse a variação de 12,9 e $31,8^{\circ} \mathrm{C}$. A temperatura ideal para o desenvolvimento da cultura é em torno de $27^{\circ} \mathrm{C}$ durante o dia. Elevadas temperaturas noturnas não são benéficas para a produção do milho, pois proporciona redução acentuada do ciclo da planta, em funçáo do incremento do somatório térmico, conforme citado por FANCELLI e Dourado Neto (2004).

Por outro lado, a precipitação pluvial total registrada durante o período experimental $(158 \mathrm{~mm})$ foi considerada baixa para o adequado desenvolvimento da cultura, 
uma vez que a literatura tem mostrado exigência média entre 350 e $500 \mathrm{~mm}$ de precipitação para que produza satisfatoriamente, sem a necessidade de irrigação (FANCELLI e Dourado Neto, 2004). Além disso, a ocorrência de três veranicos (primeiro: final da fase vegetativa; segundo: final do período de florescimento e início de enchimento de grãos; terceiro: nos 50\% finais da fase de enchimento de grãos), justificou a utilização da irrigação suplementar, especialmente no enchimento de grãos.

Os híbridos diferenciaram-se para altura de plantas, independentemente dos espaçamentos e das populações de plantas utilizadas (Tabela 1). Maior altura de planta foi observada no XB 7253, diferindo significativamente

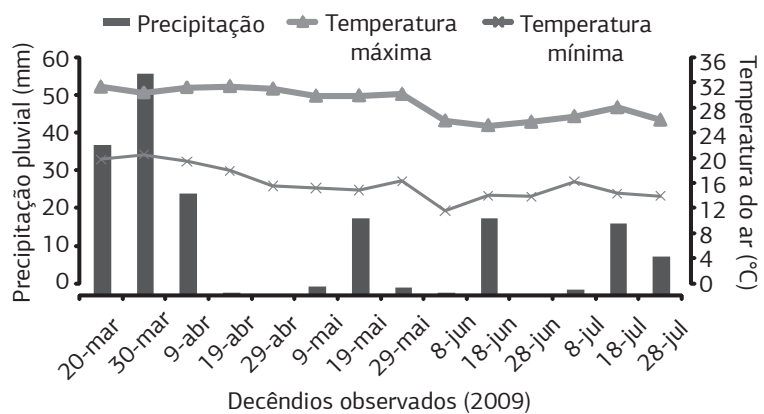

Figura 1. Precipitação pluvial e temperatura máxima e mínima do ar, por decêndio, registradas durante a condução do experimento. Selvíria (MS), Brasil (2009). dos demais genótipos. As plantas do AG 9010, considerado um híbrido de arquitetura moderna, apresentaram a menor altura. Esse fato está associado ao caráter genético, no que se refere a sua característica de superprecocidade. Esse resultado corrobora o de Alvarez et al. (2006), ao verificarem que híbridos de ciclo tardio, como o AG 1051 (duplo), proporcionaram maior altura de planta quando comparado com híbridos de ciclo precoce.

Conforme também verificado por Dourado Neto et al. (2003), a modificação no espaçamento foi dependente da alteraçáo na população para altura de planta. Constatou-se diferença entre espaçamentos apenas na populaçáo de 50.000 plantas $\mathrm{ha}^{-1}$, e a semeadura com $0,90 \mathrm{~m}$ entre linhas proporcionou plantas de maior estatura (Tabela 2). Isso é justificado pelo efeito combinado da maior competição intraespecífica por água, nutrientes (Dourado Neto et al., 2003) e luz no espaçamento de $0,90 \mathrm{~m}$, com consequente estímulo da dominância apical das plantas. Além disso, a menor oxidação de auxinas, decorrente da proximidade das plantas, estimula a elongação celular e, assim, os entrenós do colmo ficam mais longos, aumentando a estatura da planta (SANGOI et al., 2002). Os resultados foram coerentes aos obtidos por Penariol et al. (2003) no Estado de São Paulo, pois ao avaliarem o efeito de populaçôes (40.000; 60.000 e 80.000 plantas ha $^{-1}$ ) e espaçamentos $(0,40 ; 0,60$ e $0,80 \mathrm{~m}$ entre linhas) sobre

Tabela 1. Valores médios de altura de planta (AP), altura de inserção de espiga (AE), diâmetro de colmo (DC), comprimento de espiga (CE), diâmetro de espiga (DE), prolificidade (PR), massa de cem grãos (M100) e rendimento de grãos (RG) em funçáo de arranjos espaciais de plantas na cultura do milho. Selvíria (MS), Brasil (2009)

\begin{tabular}{|c|c|c|c|c|c|c|c|c|c|}
\hline \multirow{2}{*}{\multicolumn{2}{|c|}{ Tratamentos }} & AP & $A E$ & DC & CE & DE & \multirow{2}{*}{$\begin{array}{c}\text { PR } \\
\text { espiga planta }{ }^{-1}\end{array}$} & M100 & \multirow{2}{*}{$\begin{array}{c}\text { RG } \\
\text { kg ha }^{-1}\end{array}$} \\
\hline & & \multicolumn{2}{|c|}{ cm } & \multicolumn{3}{|c|}{$\mathrm{mm}$} & & g & \\
\hline \multicolumn{2}{|l|}{$\begin{array}{l}\text { Híbrido (H) } \\
\text { XB } 6010\end{array}$} & $231,0 \mathrm{~b}$ & $121,8 b$ & $19,9 \mathrm{~b}$ & 150,8 & 48,8 & $0,92 \mathrm{~b}$ & 37,5 & 6.788 \\
\hline \multicolumn{2}{|l|}{ XВ 6012} & $229,8 b$ & $142,0 \mathrm{a}$ & $19,0 \mathrm{c}$ & 153,3 & 49,2 & $0,99 a$ & 34,8 & 6.974 \\
\hline \multicolumn{2}{|l|}{ XB 7253} & 238,6 a & $145,4 \mathrm{a}$ & $18,8 \mathrm{c}$ & 161,2 & 47,9 & $0,98 \mathrm{a}$ & 36,7 & 7.664 \\
\hline \multicolumn{2}{|l|}{ XB 9003} & $214,7 c$ & $104,3 \mathrm{c}$ & 20,7 a & 152,3 & 48,4 & $0,96 a b$ & 38,5 & 7.319 \\
\hline \multicolumn{2}{|l|}{ AG 9010} & $195,1 \mathrm{~d}$ & $92,8 d$ & $19,0 \mathrm{c}$ & 142,2 & 45,6 & $0,95 a b$ & 33,1 & 6.093 \\
\hline \multicolumn{2}{|l|}{ Teste F } & $112,57^{* *}$ & 328,97 ** & 14,96 ** & 37,96 ** & 103,58 ** & 8,08 ** & 86,79 ** & 40,65 ** \\
\hline \multicolumn{10}{|c|}{ Espaçamento entre linhas (E) } \\
\hline \multicolumn{2}{|l|}{$0,45 \mathrm{~m}$} & 221,2 & 121,1 & $20,1 \mathrm{a}$ & 152,7 & 48,1 & 0,96 & 36,0 & 7.121 \\
\hline \multicolumn{2}{|l|}{$0,90 \mathrm{~m}$} & 222,5 & 121,5 & $18,9 \mathrm{~b}$ & 151,3 & 47,9 & 0,95 & 36,3 & 6.814 \\
\hline \multicolumn{2}{|l|}{ Teste F } & 0,76 & 0,21 & 31,23 * & 2,85 & 6,83 & 0,03 & 1,04 & 5,44 \\
\hline \multicolumn{10}{|c|}{ População (P) } \\
\hline \multicolumn{2}{|c|}{50.000 plantas ha-1 } & 222,3 & 118,4 & 21,6 & 163,2 & 49,1 & 1,02 & 37,4 & 6.584 \\
\hline \multicolumn{2}{|c|}{60.000 plantas ha-1 } & 220,0 & 118,7 & 20,2 & 155,4 & 48,8 & 0,98 & 36,7 & 6.804 \\
\hline \multicolumn{2}{|c|}{70.000 plantas $\mathrm{ha}^{-1}$} & 222,4 & 122,3 & 19,0 & 152,1 & 47,6 & 0,95 & 36,0 & 7.113 \\
\hline \multicolumn{2}{|c|}{80.000 plantas ha-1 } & 223,6 & 123,0 & 18,8 & 146,7 & 47,5 & 0,92 & 35,5 & 7.225 \\
\hline \multicolumn{2}{|c|}{90.000 plantas ha-1 } & 220,9 & 124,0 & 17,9 & 142,2 & 47,0 & 0,92 & 35,1 & 7.110 \\
\hline \multicolumn{2}{|l|}{ Teste F } & 0,73 & $4,05^{* *}$ & 44,78 ** & 53,54 ** & 41,63 ** & 17,01 ** & 15,36 ** & 8,15 ** \\
\hline \multirow{4}{*}{$\begin{array}{l}\text { Teste F } \\
\text { (interação) }\end{array}$} & $\mathrm{H} \times \mathrm{E}$ & 0,26 & 0,47 & 1,60 & $5,24 * *$ & 0,25 & 1,37 & $3,18^{*}$ & 4,50 ** \\
\hline & $\mathrm{H} \times \mathrm{P}$ & 1,16 & 0,88 & 0,91 & 1,50 & 2,83 ** & 0,92 & 0,68 & 2,50 ** \\
\hline & $E \times P$ & $2,76 *$ & 1,38 & 0,76 & 1,86 & 0,15 & 0,69 & 1,95 & 1,39 \\
\hline & $H \times E \times P$ & 0,79 & 0,64 & 1,20 & 1,20 & 0,42 & 0,44 & 0,92 & 1,29 \\
\hline \multicolumn{2}{|l|}{ C.V. (\%) } & 3,83 & 5,75 & 6,25 & 4,41 & 2,39 & 6,80 & 3,34 & 8,84 \\
\hline
\end{tabular}

** $\mathrm{e}^{*}$ - significativo em nível de $1 \%$ e $5 \%$ de probabilidade pelo teste $\mathrm{F}$, respectivamente. Médias seguidas por letras distintas diferem pelo teste de Tukey em nível de $5 \%$ de probabilidade. $\mathrm{CV}$ - coeficiente de variaçăo. 
Tabela 2. Desdobramento da interaçáo entre espaçamento entre linhas e população de plantas para altura de planta (cm) na cultura do milho. Selvíria (MS), Brasil (2009)

\begin{tabular}{|llcccc}
\hline Espaçamento entre linhas & \multicolumn{5}{c}{ População (plantas ha-1) } \\
\cline { 2 - 7 } & $\mathbf{5 0 . 0 0 0}$ & $\mathbf{6 0 . 0 0 0}$ & $\mathbf{7 0 . 0 0 0}$ & $\mathbf{8 0 . 0 0 0}$ & $\mathbf{9 0 . 0 0 0}$ \\
\hline $0,45 \mathrm{~m}$ & $218,2 \mathrm{~b}$ & $220,0 \mathrm{a}$ & $222,4 \mathrm{a}$ & $222,6 \mathrm{a}$ & $222,9 \mathrm{a}$ \\
$0,90 \mathrm{~m}$ & $226,4 \mathrm{a}$ & $220,1 \mathrm{a}$ & $222,3 \mathrm{a}$ & $224,5 \mathrm{a}$ & $218,9 \mathrm{a}$ \\
\hline
\end{tabular}

Médias seguidas por mesma letra nas colunas não diferem pelo teste de Tukey em nível de $5 \%$ de probabilidade.

dois genótipos de milho (AG 9010 e BR 473), observaram incremento na altura de planta com o aumento do espaçamento. Por outro lado, Demétrio et al. (2008) verificaram que a altura de planta não foi influenciada pelas alterações nos espaçamentos, evidenciando não ter ocorrido competição intraespecífica.

$\mathrm{Na}$ análise de regressão, a altura de planta não teve ajuste de equação linear ou quadrática decorrente das variaçóes na população em nenhum dos espaçamentos, discordando dos resultados obtidos por Scheeren et al. (2004), que encontraram tendência significativa no aumento da altura de planta com o incremento da densidade populacional. SiLva et al. (2008) observaram aumento linear no porte das plantas à medida que se aumentou a populaçấo de plantas de 40.000 para 80.000 plantas ha ${ }^{-1}$ no híbrido P30K75. Outros autores também constataram aumento linear na altura de planta com o incremento da densidade populacional (SANGOI et al., 2002) e atribuíram esse aumento ao efeito combinado da competiçáo intraespecífica por luz e estímulo da dominância apical das plantas.

Para altura de inserção de espiga não houve efeito de interação entre os fatores considerados, mas somente efeito independente de híbrido e de população (Tabela 1). Maior altura de inserção de espiga foi constatada nos híbridos XB 6012 e XB 7253. Nas plantas do híbrido AG 9010 observou-se a menor altura de inserção de espiga, o que é desejável na cultura, pois a menor distância entre o solo e o ponto de inserção da espiga contribui para o melhor equilíbrio da planta, minimizando a quebra de colmos, principalmente em populaçóes mais elevadas, nas quais o diâmetro desse órgão vegetativo é menor (SANGOI et al., 2002). Avaliando a influência de espaçamentos e de densidades populacionais em milho, DEMÉTRIo et al. (2008) não constataram diferença significativa entre os híbridos simples modernos P30K73 e P30F80 para inserção da espiga. Da mesma forma do que foi constatado no ensaio, outros autores também não verificaram influência de espaçamentos sobre a altura de inserção de espiga (Paulo e Andrade, 2003; Demétrio et al., 2008). No Estado do Paraná, Lana et al. (2009) avaliando o efeito da redução de espaçamento $(0,45 ; 0,75$ e $0,90 \mathrm{~m}$ entre linhas), bem como do uso de diferentes doses de $\mathrm{N}$ em cobertura $(0 ; 30 ; 60$ e 90 $\mathrm{kg} \mathrm{ha}{ }^{-1}$ ), sobre componentes de produção, rendimento e outros caracteres agronômicas do milho, constataram influência do espaçamento e da adubação nitrogenada sobre a altura de inserção de espiga; os menores valores foram obtidos com a utilização do espaçamento reduzido (0,45 m entre linhas).

Diferentemente do evidenciado para altura de planta, a altura de inserção de espiga aumentou linearmente em função do incremento na população (Figura 2a), corroborando com vários trabalhos de pesquisa (SANGOI et al., 2002; Scheeren et al., 2004), demonstrando o maior alongamento dos entrenós através do efeito combinado da competição intraespecífica, principalmente em altas populações.

O diâmetro de colmo foi influenciado pelos híbridos, espaçamentos e populaçôes, porém, sem interação significativa entre esses fatores (Tabela 1). No híbrido XB 9003 notou-se maior diâmetro de colmo, podendo-se inferir que plantas deste genótipo têm maior tolerância ao acamamento e quebramento por ocasião da colheita, sendo fundamental para a manifestação do desempenho produtivo. Plantas dos híbridos XB 6012, XB 7253 e AG 9010 não diferenciaram entre si e tiveram menor diâmetro de colmo. Nota-se que a utilizaçáo do espaçamento de 0,45 $\mathrm{m}$ entre linhas proporcionou a obtenção de plantas com maior diâmetro de colmo. Tal fato é justificado pela menor interceptação da radiação solar pelo dossel da cultura nos maiores espaçamentos (Sharratt e McWillians, 2005), favorecendo o estiolamento das plantas e a redução do diâmetro de colmo (SANGOI et al., 2002). Entretanto, a literatura sobre alteraçáo no diâmetro de colmo com a redução do espaçamento é contraditória. Penariol et al. (2003), em dois anos agrícolas, não observaram alteração do diâmetro do colmo de dois genótipos (AG 9010 e BR 473), em função de modificaçôes nos espaçamentos entre as linhas de milho.

O aumento de 50.000 para 90.000 plantas ha $^{-1}$ provocou diminuição linear do diâmetro de colmo (Figura 2b), o que está de acordo com Dourado Neto et al. (2003). Esses autores observaram que quanto maior a densidade populacional menor o diâmetro do colmo. Esse fato ocorre porque em altas populaçóes, as plantas alocam seus recursos para um crescimento mais rápido, a fim de evitar o sombreamento, aumentando a possibilidade de crescimento acima do dossel, porém, diminuindo o diâmetro de colmo e a área foliar (TAIZ e ZeIger, 2004). Outro fato é que o aumento na densidade populacional pode proporcionar redução na disponibilidade de água e nutrientes para as plantas. A redução do diâmetro de colmo com o aumento da população de plantas já foi relatada por diversos autores (SANGoI et al., 2002; Penariol et 

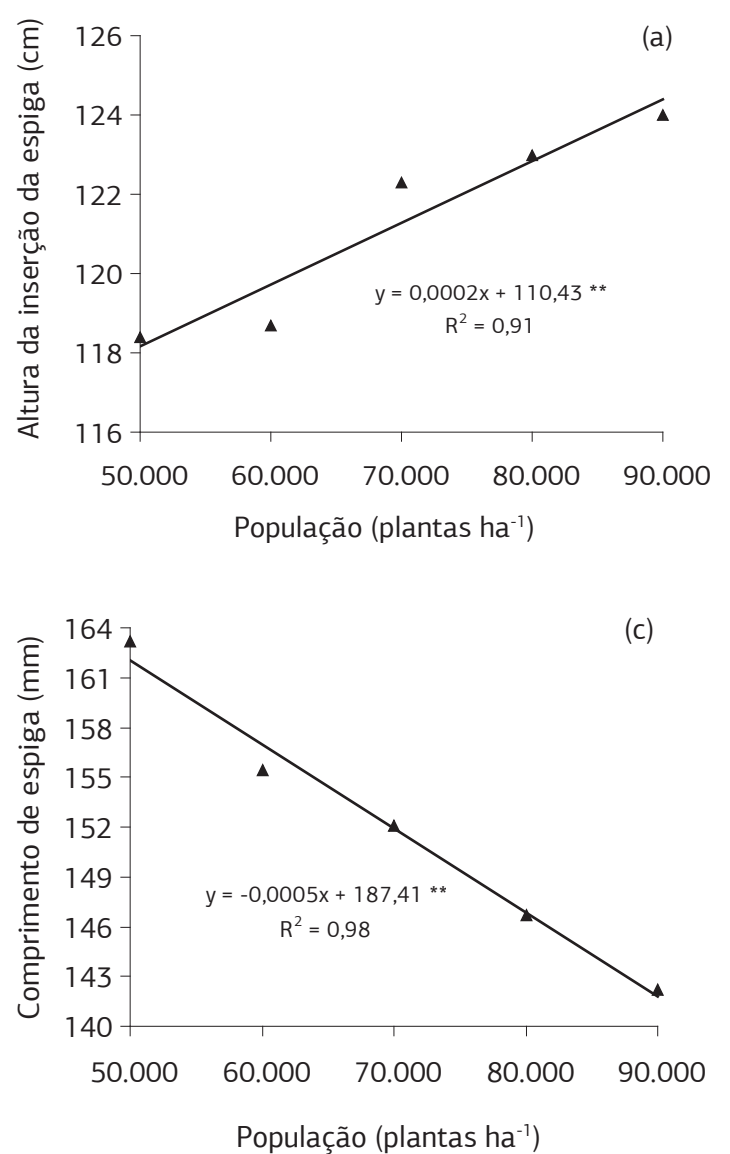
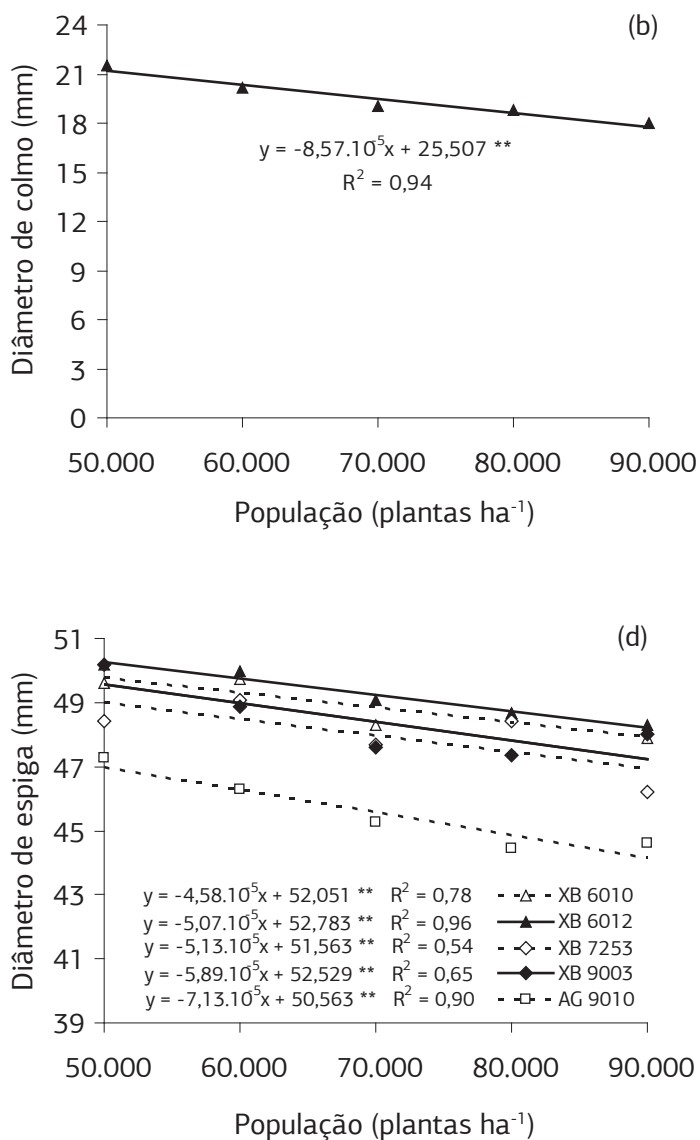

Figura 2. Altura de inserção de espiga (a); diâmetro de colmo (b); comprimento de espiga (c) e diâmetro de espiga (d); em função de populaçóes de plantas na cultura do milho. Selvíria (MS), Brasil (2009).

al., 2003) e pode limitar a utilização de altas populaçôes para híbridos de colmos menos resistentes.

Para o comprimento de espiga houve efeito de população, híbrido e da interação entre híbrido e espaçamento (Tabela 1). O aumento na população de plantas proporcionou redução linear do comprimento de espiga (Figura 2c), demonstrando que ao promover maior competiçāo intraespecífica entre as plantas de milho, há a diminuição em tamanho de determinadas estruturas das plantas de milho, como as espigas.

Os resultados do presente estudo são coerentes com os obtidos por Paulo e Andrade (2003) e Brachtvogel et al. (2009), que evidenciaram progressiva redução no comprimento de espiga em função do aumento da populaçáo. Dourado Neto et al. (2003) verificaram que, nas populaçóes compreendidas entre 30.000 e 60.000 plantas $\mathrm{ha}^{-1}$, para todos os genótipos avaliados, houve aumento do comprimento de espigas pela reduçáo do espaçamento de 0,8 para $0,4 \mathrm{~m}$. Para populaçóes acima de 65.000 plantas ha $^{-1}$, esse aumento não foi observado, provavelmente pela competição intraespecífica por água, nutrientes e luz superar os efeitos do melhor arranjo espacial entre plantas. Nenhum dos híbridos avaliados teve o comprimento de espiga afetado pelos espaçamentos (Tabela 3). Por outro lado, no espaçamento de $0,45 \mathrm{~m}$ entre linhas, os híbridos XB 7253 e XB 9003 obtiveram maior comprimento de espiga, ao passo que, no espaçamento de $0,90 \mathrm{~m}$, os maiores valores foram constatados nos híbridos XB 7253 e XB 6012.

$\mathrm{Na}$ avaliação do diâmetro de espiga, não houve efeito significativo de espaçamento, mas apenas interação entre híbrido e população (Tabela 1). Os híbridos tiveram o mesmo comportamento quando submetidos às populações de $60.000,70.000$ e 80.000 plantas ha $^{-1}$, constatando-se menor diâmetro de espiga no híbrido AG 9010 (Figura 2d). Nas populaçóes de 50.000 e 90.000 plantas ha ${ }^{-1}$, os híbridos XB 6010, XB 6012 e XB 9003 tiveram maior diâmetro de espiga. $\mathrm{O}$ aumento da população provocou diminuição linear do diâmetro de espiga para todos os híbridos, como também observado por BRACHTVOGEL et al. (2009).

A prolificidade, que expressa o número de espigas por planta, não propiciou alteração com a redução do espaçamento (Tabela 1). Outros autores, trabalhando com híbridos de milho em diferentes locais e anos agrícolas, também não observaram variação na prolificidade com a redução do espaçamento (Argenta et al., 2001; Penariol et al., 2003; Scheeren et al., 2004). Houve efeito independente de híbridos e de populações, e XB 6012 e 
Tabela 3. Desdobramento da interação entre híbrido e espaçamento entre linhas para comprimento de espiga (mm) na cultura do milho. Selvíria (MS), Brasil (2009)

\begin{tabular}{|c|c|c|c|c|c|}
\hline \multirow{2}{*}{ Espaçamento entre linhas } & \multicolumn{5}{|c|}{ Híbrido } \\
\hline & XВ 6010 & ХВ 6012 & ХВ 7253 & ХВ 9003 & AG 9010 \\
\hline $0,45 \mathrm{~m}$ & $149,3 \mathrm{aBC}$ & $151,5 \mathrm{aBC}$ & $161,6 \mathrm{aA}$ & $155,5 \mathrm{aAB}$ & $145,2 \mathrm{aC}$ \\
\hline $0,90 \mathrm{~m}$ & $152,4 \mathrm{aB}$ & $155,1 \mathrm{aAB}$ & $160,7 \mathrm{aA}$ & $149,0 \mathrm{aB}$ & $139,1 \mathrm{aC}$ \\
\hline
\end{tabular}

Médias seguidas por mesma letra minúscula nas colunas e por mesma letra maiúscula nas linhas não diferem pelo teste de Tukey em nível de $5 \%$ de probabilidade.

XB 7253 tiveram maior prolificidade, apesar de não terem se diferenciado dos híbridos XB 9003 e AG 9010.

$\mathrm{O}$ incremento da população de plantas proporcionou decréscimo linear no número de espiga por planta (Figura 3a). Esse fato ocorre porque, em baixas densidades populacionais, a competição entre as plantas por água, luz e nutrientes é pequena, disponibilizando às plantas os recursos necessários para o enchimento dos grãos em mais de uma espiga por planta. Resultados similares foram obtidos por Argenta et al. (2001), Penariol et al. (2003), Cruz et al. (2007) e Silva et al. (2008). O aumento no número de plantas por área, até determinado limite, tende a compensar a diminuição do tamanho das espigas. Os melhores rendimentos de grãos são conseguidos naquelas populaçóes cuja prolificidade esteja próxima da unidade, com espigas de tamanho suficiente para não diminuir o rendimento de grãos.

Importante componente de produção na cultura do milho, a massa de cem gráos comportou-se de maneira similar à prolificidade ao ser afetada pela população de plantas, independentemente de híbrido e de espaçamento (Tabela 1), o que contraria Borrás et al. (2003), que relataram que esse é o componente de produção menos afetado por variaçóes nas práticas de manejo. A massa de cem grãos decresceu linearmente conforme se aumentou a população de plantas (Figura 3b), demonstrando que o incremento na população altera a taxa e duração do período de enchimento dos grãos. Os dados obtidos corroboram com os conseguidos por Strieder et al. (2007), no Estado do Rio Grande do Sul, que avaliaram variação de população em quatro espaçamentos $(0,4 ; 0,6 ; 0,8$ e 1,0 m entre linhas) nos híbridos Flash e Attack.

Pelo desdobramento da interação significativa entre híbrido e espaçamento (Tabela 4), verifica-se que somente o híbrido AG 9010 proporcionou variação na massa de cem grãos em funçáo do espaçamento, constatando-se maior massa de gráos quando submetido ao espaçamento de $0,90 \mathrm{~m}$ entre linhas. Era de esperar que no espaçamento reduzido a massa média dos grãos fosse maior, em virtude da menor competição entre as plantas por nutrientes, luz e água no solo, além de conferir maior capacidade de interceptação de radiação solar. Os genótipos tiveram o mesmo comportamento em ambos os espaçamentos, com o híbrido XB 9003 destacando-se pela maior massa
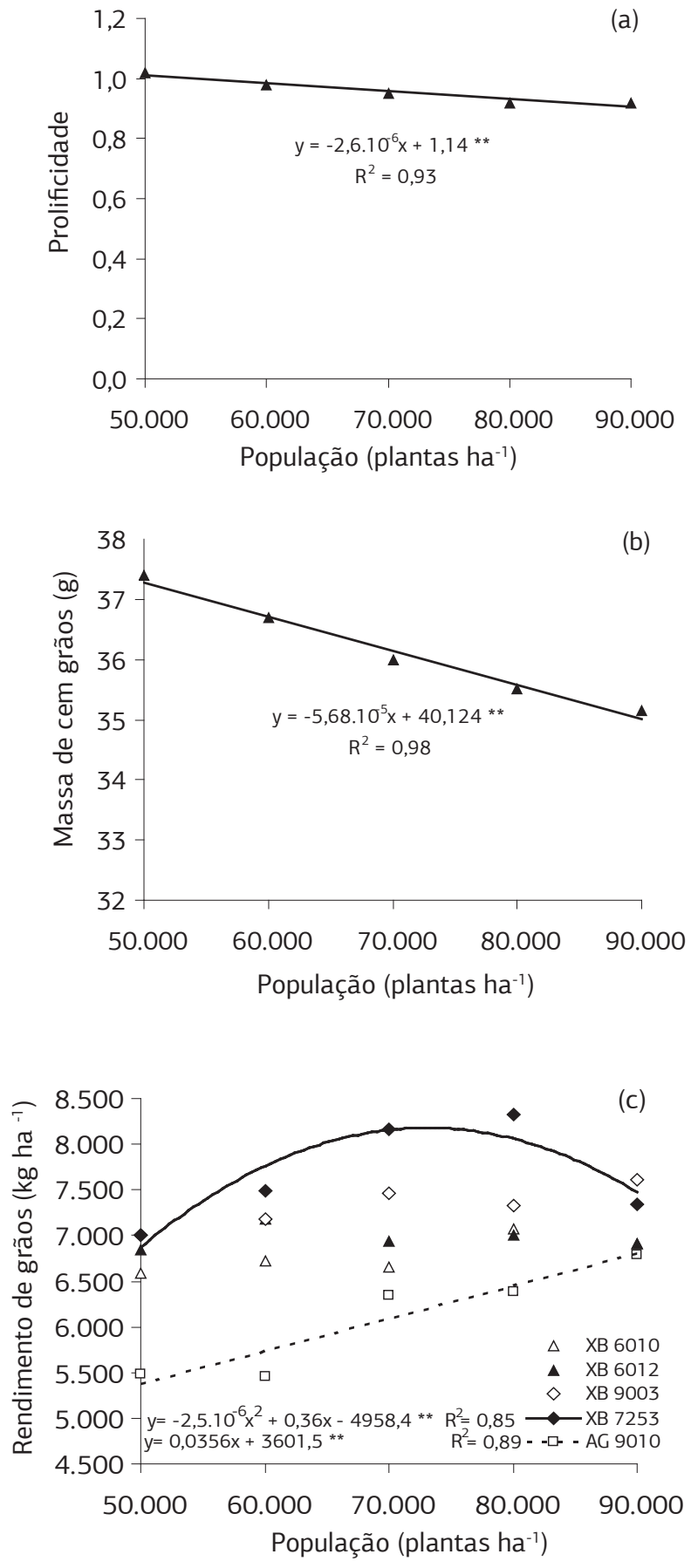

Figura 3. Prolificidade (a); massa de cem grãos (b) e rendimento de grãos (c), em função de populaçôes de plantas na cultura do milho. Selvíria (MS), Brasil (2009). 
de grãos obtida, apesar de não ter se diferenciado do XB 6010 .

No rendimento de grãos, verificou-se comportamento distinto em razão da interação entre híbrido e espaçamento e híbrido e população (Tabela 1), corroborando com os resultados de Penariol et al. (2003). Contudo, Cruz et al. (2007) constataram que o rendimento foi influenciado pela interação significativa entre espaçamento e densidades de semeadura em dois anos agrícolas. O híbrido AG 9010 tem menor rendimento de grãos no espaçamento de 0,90 m (Tabela 5), indicando claramente que para este genótipo, que possui arquitetura moderna, a redução do espaçamento é vantajosa. Ganhos em rendimento de grãos com uso de espaçamento reduzido na cultura do milho foram obtidos por outros autores (Dourado Neto et al., 2003; Penariol et al., 2003). Contudo, os demais genótipos não tiveram o rendimento de grãos alterado em função dos espaçamentos entre linhas adotados. $\mathrm{Na}$ análise do desempenho dos híbridos dentro de cada espaçamento, verificou-se que os híbridos XB 7253 e XB 9003 tiveram maior rendimento quando cultivados no espaçamento de $0,45 \mathrm{~m}$. Esse fato foi observado também no espaçamento de $0,90 \mathrm{~m}$, porém, não se diferenciando significativamente do híbrido XB 6012.

No tocante aos genótipos dentro de cada população (Tabela 6), os híbridos XB 6010, XB 6012, XB 7253 e XB 9003 apresentaram os maiores rendimentos de grãos com 50.000 e 60.000 plantas ha ${ }^{-1}$. Em condiçôes de 70.000 e 80.000 plantas ha $^{-1}$, a superioridade produtiva foi constatada apenas nos híbridos XB 7253 e XB 9003. $\mathrm{Na}$ populaçáo de 90.000 plantas ha ${ }^{-1}$, não houve diferença significativa entre os híbridos. Apenas com os resultados dos híbridos XB 7253 e AG 9010, permitiram-se efetuar ajustes de equações significativas pela análise de regressão (Figura 3c). O modelo quadrático foi o que melhor se ajustou às médias do híbrido XB 7253 , tendo rendimento máximo estimado de $8.000 \mathrm{~kg} \mathrm{ha}^{-1}$ com a utilizaçáo de 72.000 plantas ha $^{-1}$. O rendimento de grãos do AG 9010 aumentou linearmente com o incremento na populaçáo de plantas, podendo-se inferir que para cada aumento de 1000 plantas ha ${ }^{-1}$, ocorreu acréscimo de 35,6 $\mathrm{kg} \mathrm{ha}^{-1}$ no rendimento. Esta resposta pode ser atribuída à melhor ocupaçáo da área e melhor aproveitamento dos recursos disponíveis, principalmente da luz. Devido à arquitetura moderna de plantas, o aumento da populaçáo de plantas desse híbrido permite a colheita de maior número de espigas por hectare, aumentando consequentemente o rendimento de grãos por hectare. A diminuição do tamanho das espigas com o incremento na população (Figura 2c, d) é suplantada pelo aumento do número delas neste caso.

Resultados similares foram observados por Penariol et al. (2003) ao constatarem comportamento distinto entre dois genótipos de milho quando submetidos a densidades de semeadura. Os referidos autores evidenciaram que

Tabela 4. Desdobramento da interação entre híbrido e espaçamento entre linhas para massa de cem grãos (g) na cultura do milho. Selvíria (MS), Brasil (2009)

\begin{tabular}{|llllll|}
\hline Espaçamento entre linhas & \multicolumn{5}{c}{ Híbrido } \\
\cline { 2 - 5 } & XB 6010 & XB 6012 & XB 7253 & XB 9003 & AG 9010 \\
\hline $0,45 \mathrm{~m}$ & $37,6 \mathrm{aAB}$ & $34,6 \mathrm{aC}$ & $36,6 \mathrm{aB}$ & $38,7 \mathrm{aA}$ & $32,5 \mathrm{bD}$ \\
$0,90 \mathrm{~m}$ & $37,4 \mathrm{aAB}$ & $35,1 \mathrm{aC}$ & $36,8 \mathrm{aB}$ & $38,3 \mathrm{aA}$ & $33,8 \mathrm{aD}$ \\
\hline
\end{tabular}

Médias seguidas por mesma letra minúscula nas colunas e por mesma letra maiúscula nas linhas não diferem pelo teste de Tukey em nível de $5 \%$ de probabilidade.

Tabela 5. Desdobramento da interação entre híbrido e espaçamento entre linhas para rendimento de grãos $\left(\mathrm{kg}\right.$ ha $\left.{ }^{-1}\right)$ na cultura do milho. Selvíria (MS), Brasil (2009)

\begin{tabular}{|llllll|}
\hline Espaçamento entre linhas & \multicolumn{5}{c}{ Híbrido } \\
\cline { 2 - 6 } & XB 6010 & XB 6012 & XB 7253 & XB 9003 & AG 9010 \\
\hline $0,45 \mathrm{~m}$ & $6.835 \mathrm{aC}$ & $6.914 \mathrm{aBC}$ & $7.776 \mathrm{aA}$ & $7.496 \mathrm{aAB}$ & $6.582 \mathrm{aC}$ \\
$0,90 \mathrm{~m}$ & $6.740 \mathrm{aB}$ & $7.033 \mathrm{aAB}$ & $7.551 \mathrm{aA}$ & $7.142 \mathrm{aAB}$ & $5.605 \mathrm{bC}$ \\
\hline
\end{tabular}

Médias seguidas por mesma letra minúscula nas colunas e por mesma letra maiúscula nas linhas não diferem pelo teste de Tukey em nível de 5\% de probabilidade.

Tabela 6. Desdobramento da interação entre híbrido e população de plantas para rendimento de grãos $\left(\mathrm{kg}\right.$ ha $\left.{ }^{-1}\right)$ na cultura do milho. Selvíria (MS), Brasil (2009)

\begin{tabular}{|c|c|c|c|c|c|}
\hline \multirow{2}{*}{ Híbrido } & \multicolumn{5}{|c|}{ População (plantas ha-1) } \\
\hline & 50.000 & 60.000 & 70.000 & 80.000 & 90.000 \\
\hline XB 6010 & $6.591 \mathrm{ab}$ & $6.719 \mathrm{a}$ & 6.648 bc & $7.070 \mathrm{~b}$ & $6.910 \mathrm{a}$ \\
\hline XB 6012 & $6.837 \mathrm{a}$ & $7.182 \mathrm{a}$ & $6.937 \mathrm{bc}$ & $7.003 \mathrm{~b}$ & $6.909 \mathrm{a}$ \\
\hline XB 7253 & $7.008 \mathrm{a}$ & $7.484 \mathrm{a}$ & $8.160 \mathrm{a}$ & $8.330 \mathrm{a}$ & $7.336 \mathrm{a}$ \\
\hline XB 9003 & $7.006 \mathrm{a}$ & $7.181 \mathrm{a}$ & $7.468 \mathrm{ab}$ & $7.333 \mathrm{ab}$ & $7.606 \mathrm{a}$ \\
\hline AG 9010 & $5.480 \mathrm{~b}$ & $5.455 b$ & $6.351 \mathrm{c}$ & $6.390 \mathrm{~b}$ & $6.792 \mathrm{a}$ \\
\hline
\end{tabular}

Médias seguidas por mesma letra nas colunas nấo diferem pelo teste de Tukey em nível de $5 \%$ de probabilidade. 
o híbrido AG 9010 teve aumento linear de rendimento de grãos com o aumento da densidade de plantas, enquanto a variedade BR 473 mostrou resposta quadrática em relaçáo ao aumento populacional, com um ponto máximo de $4.770 \mathrm{~kg} \mathrm{ha}^{-1}$ de rendimento, alcançado com população em aproximadamente 71.000 plantas $_{\text {ha }}{ }^{-1}$. RESENDE et al. (2003), trabalhando com espaçamentos de 0,45, 0,70 e 0,90 m e densidades de 55.000, 70.000 e 90.000 plantas $\mathrm{ha}^{-1}$, também constataram aumento linear no rendimento de grãos com o aumento na densidade de semeadura, independentemente dos genótipos avaliados. Os aumentos no rendimento de grãos com o aumento na populaçáo de plantas também foram constatados nos trabalhos de ALvarez et al. (2006) e SiLva et al. (2008). Nota-se que para híbridos com folhas eretas e menor estatura, a população ideal tende a ser maior. No entanto, essa população ideal para cada híbrido também pode ser menor se a lavoura for submetida a algum estresse ambiental.

\section{CONCLUSÃO}

Independentemente do híbrido e da população de plantas, a utilização de $0,45 \mathrm{~m}$ entre linhas proporciona a obtenção de plantas com maior diâmetro de colmo. Diâmetro de colmo, comprimento e diâmetro de espiga, prolificidade e massa de 100 grâos diminuem linearmente à medida que se aumenta o número de plantas, ao passo que a altura de planta não é afetada.

O rendimento de grãos é influenciado pelos arranjos espaciais de plantas, ocorrendo respostas diferenciadas dos híbridos, destacando-se: AG 9010 - 90.000 plantas ha $^{-1}$ no espaçamento de $0,45 \mathrm{~m}$ entre linhas; XB 7253 72.000 plantas $\mathrm{ha}^{-1}$ nos dois espaçamentos; e XB 6010, XB 6012 e XB 9003 - sem resposta significativa aos arranjos espaciais, podendo ser recomendado 50.000 plantas ha- ${ }^{-1} \mathrm{em}$ ambos os espaçamentos.

\section{AGRADECIMENTOS}

À Coordenação de Aperfeiçoamento de Pessoal de Ensino Superior - CAPES, pela bolsa de estudo concedida ao primeiro autor.

\section{REFERÊNCIAS}

ALVAREZ, C.G.D.; VON PINHO, R.G.; BORGES, I.D. Avaliação de características agronômicas e de produção de forragem e grãos de milho em diferentes densidades de semeadura e espaçamentos entre linhas. Ciência e Agrotecnologia, v.30, p.402-408, 2006.

ARGENTA, G.; SILVA, P.R.F.; BORTOLINI, C.G.; FORSTHOFER, E.L.; MANJABOSCO, E.A.; BEHEREGARAY
NETO, V. Resposta de híbridos simples de milho à redução do espaçamento entre linhas. Pesquisa Agropecuária Brasileira, v.36, p.71-78, 2001.

BORRÁS, L.; MADDONNI, G.A.; OTEGUI, M.E. Leaf senescence in maize hybrids: plant population, row spacing and kernel set effects. Field Crops Research, v.82, p.13-26, 2003.

BRACHTVOGEL, E.L.; PEREIRA, F.R.S.; CRUZ, S.C.S.; BICUDO, S.J. Densidades populacionais de milho em arranjos espaciais convencional e equidistante entre plantas. Ciência Rural, v.39, p.2334-2339, 2009.

CARDOSO, M.J.; CARVALHO, H.W.L.; SANTOS, M.X.; LEAL, M.L.S.; OLIVEIRA, A.C. Desempenho de híbridos de milho na região meio-norte do Brasil. Revista Brasileira de Milho e Sorgo, v.2, p.43-52, 2003.

CONAB - Companhia Nacional de Abastecimento. Acompanhamento de safra brasileira: grãos, décimo levantamento, julho/2010. Brasília, DF: Conab, 2010. 43p.

COSTA, A.C.S.; FERREIRA, J.C.; SEIDEL, E.P.; TORMENA, C.A.; PINTRO, J.C. Perdas de nitrogênio por volatilização da amônia em três solos argilosos tratados com uréia. Acta Scientiarum Agronomy, v.26, p.467-473, 2004.

CRUZ, J.C.; PEREIRA, F.T.F.; PEREIRA FILHO, I.A.; OLIVEIRA, A.C.; MAGALHÁES, P.C. Resposta de cultivares de milho à variação em espaçamento e densidade. Revista Brasileira de Milho e Sorgo, v.6, p.60-73, 2007.

DEMÉTRIO, C.S.; FORNASIERI FILHO, D.; CAZETTA, J.O.; CAZETTA, D.A. Desempenho de híbridos de milho submetidos a diferentes espaçamentos e densidades populacionais. Pesquisa Agropecuária Brasileira, v.43, p.1691-1697, 2008.

DIDONET, A.D.; RODRIGUES, O.; MARIO, J.L.; IDE, F. Efeito da radiação solar e temperatura na definição do número de grãos de milho. Pesquisa Agropecuária Brasileira, v.37, p.933-938, 2002.

DOURADO NETO, D.; PALHARES, M.; VIEIRA, P.A.; MANFRON, P.A.; MEDEIROS, S.L.P.; ROMANO, M.R. Efeito da população de plantas e do espaçamento sobre a produtividade de milho. Revista Brasileira de Milho e Sorgo, v.2, p.63-77, 2003.

EMBRAPA - Empresa Brasileira de Pesquisa Agropecuária. Centro Nacional de Pesquisa de Solos. Sistema brasileiro de classificação de solos. 2.ed. Brasília, DF: Embrapa-SPI; Rio de Janeiro: Embrapa Solos, 2006. 306p.

FANCELLI, A.L.; DOURADO NETO, D. Produçâo de milho. 2.ed. Guaíba: Agropecuária, 2004. 360p.

LANA, M.C.; WOYTICHOSKI JÚNIOR, P.P.; BRACCINI, A.L.; SCAPIM, C.A.; ÁVILA, M.R.; ALBRECHT, L.P. Arranjo espacial e adubação nitrogenada em cobertura na cultura do milho. Acta Scientiarum Agronomy, v.31, p.433-438, 2009.

PAULO, E.M.; ANDRADE, J.A.C. Comportamento de um milho híbrido hiperprecoce em dois espaçamentos e diferentes populaçóes de plantas. Cultura Agronômica, v.12, p.77-88, 2003. 
PENARIOL, F.G.; FORNASIERI FILHO, D.; COICEV, L.; BORDIN, L.; FARINELLI, R. Comportamento de cultivares de milho semeadas em diferentes espaçamentos entre linhas e densidades populacionais, na safrinha. Revista Brasileira de Milho e Sorgo, v.2, p.52-60, 2003.

PIMENTEL GOMES, F; GARCIA, C.H. Estatística aplicada a experimentos agronômicos e florestais: exposição com exemplos e orientaçóes para uso de aplicativos. Piracicaba: FEALQ, 2002. 309p.

RAIJ, B. van; CANTARELLA, H.; QUAGGIO, J.A.; FURLANI, A.M.C. Recomendaçóes de adubação e calagem para o Estado de São Paulo. 2.ed. Campinas: Instituto Agronômico, 1996. 285p. (Boletim Técnico, 100)

RESENDE, S.G.; VON PINHO, R.G.; VASCONCELOS, R.C. Influência do espaçamento entre linhas e da densidade de plantio no desempenho de cultivares de milho. Revista Brasileira de Milho e Sorgo, v.2, p.34-42, 2003.

RODRIGUES, L.R.; GUADAGNIN, J.P.; PORTO, M.P. Indicaçôes técnicas para o cultivo de milho e de sorgo no Rio Grande do Sul: safras 2009/2010 e 2010/2011. Veranópolis: FEPAGRO-Serra, 2009. 179p.

SANGOI, L.; ALMEIDA, M.L.; GRACIETTI, M.A.; BIANCHET, P. Sustentabilidade do colmo em híbridos de milho de diferentes épocas de cultivo em função da densidade de plantas. Revista de Ciências Agroveterinárias, v.1, p.60-66, 2002.
SANGOI, L.; SILVA, P.R.F.; SILVA, A.A.; ERNANI, P.R.; HORN, D.; STRIEDER, M.L.; SCHMITT, A.; SCHWEITZER, C. Desempenho agronômico de cultivares de milho em quatro sistemas de manejo. Revista Brasileira de Milho e Sorgo, v.5, p.218231, 2006.

SCHEEREN, B.R.; BAZONI, R.; BONO, J.A.; ARIAS, S.S.; OLIVEIRA, R.; SALOMÃO, L. Arranjo populacional para a cultura do milho na regiáo central do Estado de Mato Grosso do Sul. Acta Scientiarum Agronomy, v.26, p.55-60, 2004.

SHARRATT, B.S.; McWILLIANS, D.A. Microclimatic and rooting characteristics of narrow-row versus conventional-row corn. Agronomy Journal, v.97, p.1129-1135, 2005.

SILVA, A.G.; CUNHA JUNIOR, C.R.; ASSIS, R.L.; IMOLESI, A.S. Influência da população de plantas e do espaçamento entre linhas nos caracteres agronômicos do híbrido de milho P30K75 em Rio Verde, Goiás. Bioscience Journal, v.24, p.89-96, 2008.

STRIEDER, M.L.; SILVA, P.R.F.; ARGENTA, G.; RAMBO, L.; SANGOI, L.; SILVA, A.A.; ENDRIGO, P.C. A resposta do milho irrigado ao espaçamento entrelinhas depende do híbrido e da densidade de plantas. Ciência Rural, v.37, p.634-642, 2007.

TAIZ, L.; ZEIGER, E. Fisiologia vegetal. 3.ed. Porto Alegre: Armed, 2004. 710p. 